\title{
Designing Learner Centric MOOC
}

\author{
Umesh A. Kamerikar ${ }^{1}$, Mahadev S. Patil ${ }^{2}$ \\ Rajarambapu Institute of Technology, Rajaramnagar, Maharashtra, India \\ ${ }^{1}$ umesh.kamerikar@ ritindia.edu, ${ }^{2}$ mahadev.patil@ ritindia.edu
}

\begin{abstract}
Massive Open Online Courses (MOOCs) have become popular for diverse learners to upgrade their knowledge and skills. New Instructors are creating MOOCs which focus on the use of technology features to create space of their classroom actions. It is necessary to be aware of the technology affordances at diversity level but it is more important to focus on the pedagogy of how to use the MOOC features effectively to promote student engagement and learning. Hence MOOC instructors need a set of design principles and guidelines to create a learner-centric MOOC. In this paper, we will discuss the Learner-Centric MOOC (LCM) model, and how to apply it to create effective MOOCs. It is implemented for some points in Power Electronics course Final year B Tech students and learning analysis was carried out to find its impact on learning.
\end{abstract}

Keywords: LeD, LbD, LxI, LxT, AQ, RQ

\section{Introduction}

MOOCs or Massive Open Online Courses are one way to make quality educational content accessible to a large number of learners. Many of us may have completed MOOC or may have been teaching assistants, while others may have created our own MOOCs but completion rate is low[1] and there is lack of engagement by learners, discussion is scattered in forums[2]. New Instructors to MOOCs try to focus on using the technology affordances of the platform in order to create scene of their classroom actions. While it is necessary to be aware of the technology affordances, that only is not sufficient. It is important to concentrate on the pedagogy to exploit the technology features in order to promote student engagement and learning. A learner-centric approach is broad pedagogic principle which is effective for student engagement and learning in various settings[3]. It incorporates principles of Active learning, Peer learning, Formative assessment and so on.

We will discuss how to embed learner-centric principles in a MOOC development and create a Learner-Centric MOOC for the course. MOOC should be instead of simply having videos for watching, there are activities that need to be done, there are discussions that need to be engaged in and so on.

Arrival of internet in the 1990s had brought in the opportunity for increasing access of education through online learning. The Alliance for Lifelong Learning, a nonprofit initiative started by Oxford, Yale and Stanford University in 2000 is one of the earlier initiatives that tried to offer courses at scale through the online medium. The most widely talked about experiment in the massive open online course was the course 'Connectivism and Connective knowledge offered by Stephen Downes and George Siemens in 2008 in which 2200 participants worldwide.The next big revolution in the online offerings came in the year 2011, when the Stanford University offered three courses online. One of it was the course 'Introduction to Artificial Intelligence offered by Professor Sebastian Thrun along with Peter Norvig. This attracted 160,000 learners with around 20,000 of them completing this course.

Professor Thrun went on to create a MOOC platform Udacity in the year 2012, a year that also saw the birth of the most popular MOOC platforms like Coursera, edX, Future Learn, Open HPI, Eli Academy etc. India had also witnessed scaling up initiatives in the field of education during these years. With the Train 10,000 Teachers coming up with blended course offerings using its synchronous remote center model for content delivery and the National program on technology enhanced learning coming up with video repositories from professors of the premier institutes like IITs and IISc. Thus, MOOCs had become a common word by 2012 and the advantages of these courses in terms of access and flexibility that it provides for learners along with the scales that its reach was widely spread crossing all boundaries.

\section{Why LCM}

Many of us are familiar with learner centric in the classroom. We are used to hearing terms like active learning, group discussions, peer-learning and are aware of the benefits of incorporating such techniques in the classroom. We need to make learners go beyond simply listening to the lectures, taking notes, and executing prescribe procedures to immediate practice, figure things out, express their thinking and learn from peers. It needs to change from how well am I explaining the concept to how well be learners learning the concept.

Normally MOOC contains set of videos, a set of practice question, set of resources and a place for discussion. In this opportunities for micro-application are missing, formative assessment and customized feedbacks are missing for attention to learner and motivation. Also, if you just make a discussion forum available there are no explicit activities to foster peer-learning and there is no connection of the instructor to the learner.

Hence instructor has to design mechanisms which encourage students to go through all the resources 
Journal of Engineering Education Transformations, Volume 33, January 2020, Special issue, eISSN 2394-1707 provided, guide their directions in which they want to carry their learning and ensure that they have actually benefited in learning from looking at those resources in a meaningful manner. Also the instructor has to ensure that students learn from peers reviews.

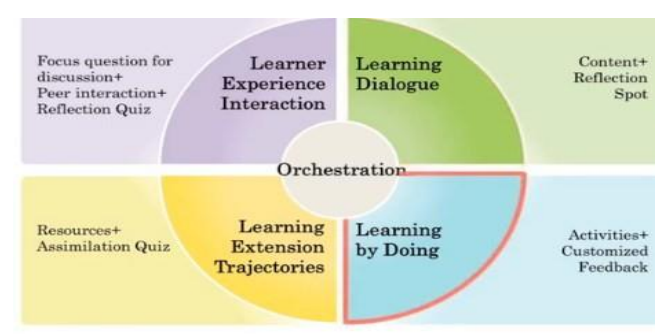

Fig1. LCM Model

To achieve this Learner-Centric MOOC model, which has Learning Dialogues(LeD), Learning by Doing(LbD), Learning Extension Trajectories(LxT), Learner Experience Interactions(LxI), all of which are connected through appropriate orchestration between the course team and the learners, to ensure that the learners are not simply watching the information but are able to assimilate them in a meaningful manner.

The LCM model mainly consists of Learning Dialogues which advance concept understanding through learner interaction, Learning by Doing is formative assessment activity, Learning Extension Trajectories advance learners learning along diverse paths, Learning Experience Interactions cultivates peer-learning through focused discussion. In addition to these elements, it is important to keep in mind the orchestration, i.e. the process by which the course team designs the interactions for the learners as well as assists and guides the learners through the MOOC.

\section{Learning Dialogues (LeD)}

LeD consists of content which could be a short video explanation, or it could be some text which the instructor wants the learner to read, or it could be an animation.

The reflection spot in a LeD is a logical point where instructor provides the learner with opportunities for micropractice, to assimilate what they have just learned as well as to express their opinion or interact with the content in some way. It's a structural point where the learners may get disengaged. Learner can respond to multiple-choice question, or a fill in the blanks, or as a short answer question.

Fig2. LeD Structure

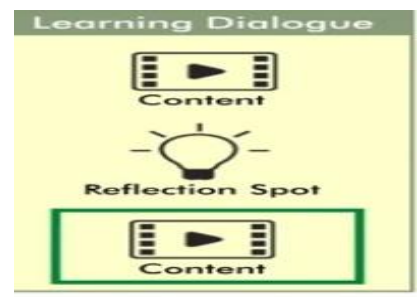

Content may be a summary of what were the expected answers in the reflection spot, or it may be continuing further from the reflection spot.
The goal of a learning dialogue is to provide this conceptual knowledge along with explicit spots for learners to express their conceptions, do micro-practice and reflect on what they have learnt. Learning dialogue promotes concept acquisition through learner interaction.

\section{Making a LeD}

\section{If it is video following way are taken}

- Talking head video, which is the instructor speaking to the camera. It is useful where we have some narrative to tell.

- Slides can be used for takeaways and there is emphasis on the content using the textual features. Use $6 \times 6$ rule i.e. e slide will not have more than six bullets, at the same time every bullet will not have more than six words.

- Picture in picture

- Writing on paper or a digital tablet or even a blackboard or a whiteboard and is being captured by some gadget, it could be a camera or a screen capture mechanism.

- Screen capture, Graphics, Animation etc.

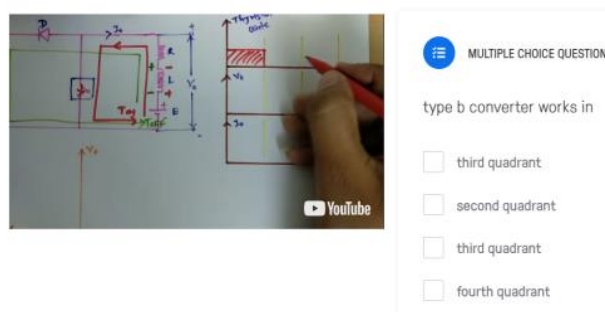

Fig3. LeD implementation with Reflection spot

For creation of Led, identify the pause points in a lecture in order to identify the topics and the chunks that constitute an LeD, and then to identify the points in an LeD, where we want to provide learner engagement, and connect by introducing reflection spots. In some cases, you may have the reflection spot may be in the beginning/middle /towards the end of the LeD. One point to keep in mind is that it is necessary to close the loop for the learner by providing a commentary on what could be the different responses that the learners have given in the content that follows the reflection spot. This ensures that a LeD is truly a dialogue between the instructor and a learner, and not simply a one- way transmission of information.

\section{Learning by Doing (LbD)}

It is a formative assessment activity designed by an instructor for students to self-check their level of concept attainment[4], or for them to immediately apply the concepts that they have seen and learnt in the LeD, or for integration of various concepts and various parts of the module in the MOOC. LbDs can be in the form of multiple choice questions or they can require longer responses in the form of a text box or so on. The main goal of an LbD is formative assessment. Learners perform an LbD activity 
Journal of Engineering Education Transformations, Volume 33, January 2020, Special issue, eISSN 2394-1707

right after which, they receive rapid, specific, and constructive feedback not right or wrong but telling the

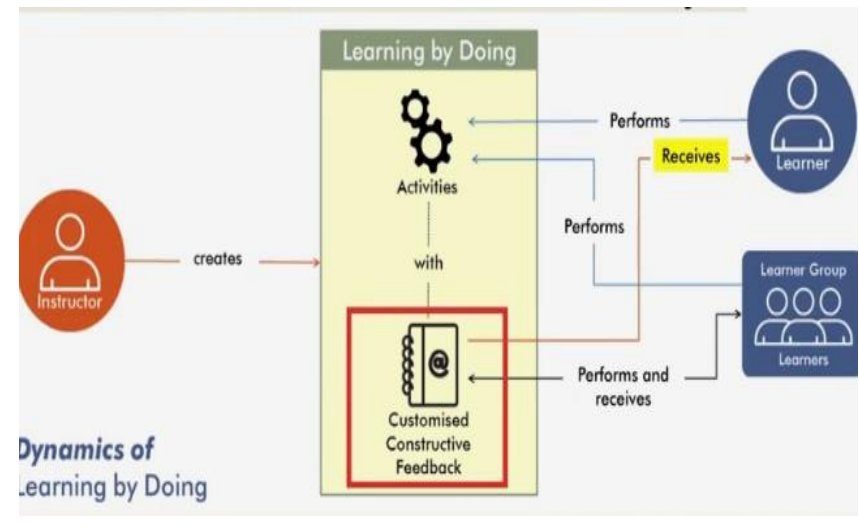

Fig4. LbD Structure

learner what they can do, what are the resources they can access, what they should revise and so on, so that they can get their reasoning and their response correct. Each option has its own specific constructive feedback that helps the learner figure out exactly what went wrong and how to fix it. Formative assessment primary goal is not to grade the learner but to provide feedback to the learners so that they can improve their learning.

An LbD provides an immediate application of concepts seen. LbDs appear right after the content LeDs, not only at the end of the module. LbDs or Learning by Doing can be in the format of multiple choice questions, but they can even go beyond. As we saw they can be longer assignments or problems. The feedback in such LbDs is provided via peer review, so Learning by Doing activities are learner- centric in the sense they exploit the power of peer learning. The process of peer review helps both the giver of the feedback and the receiver of the feedback.

Each LeD should be followed by LbD activities with customized constructive feedback.

- LbD activities

- $\quad$ MCQ, True/ False

- $\quad$ Long answer

- $\quad$ Problem solving

- Pair matching and many more

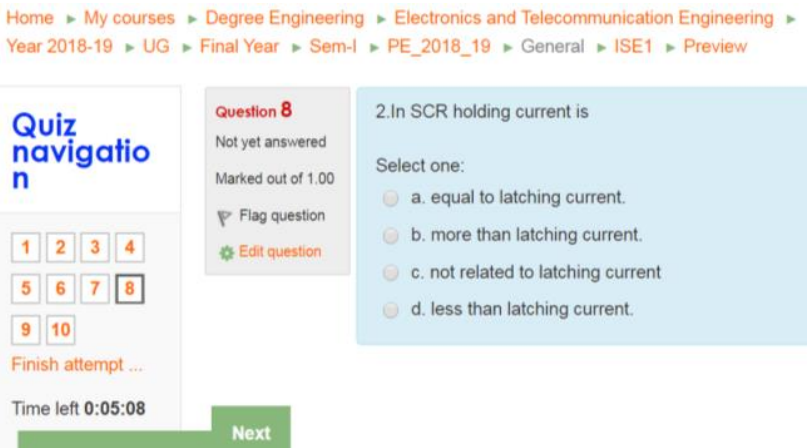

Fig5. LbD activity (Quiz) using MOODLE
While creating an LbD activity, we need to start with the learning goal, "is it concept attainment, application, integration of knowledge". We can use our teaching experience to decide the pedagogical goal and the pedagogical type and we need to explore the platform to decide the format of the question and then combine all this using our creativity.

\section{Learning Extension Trajectories (LxT)}

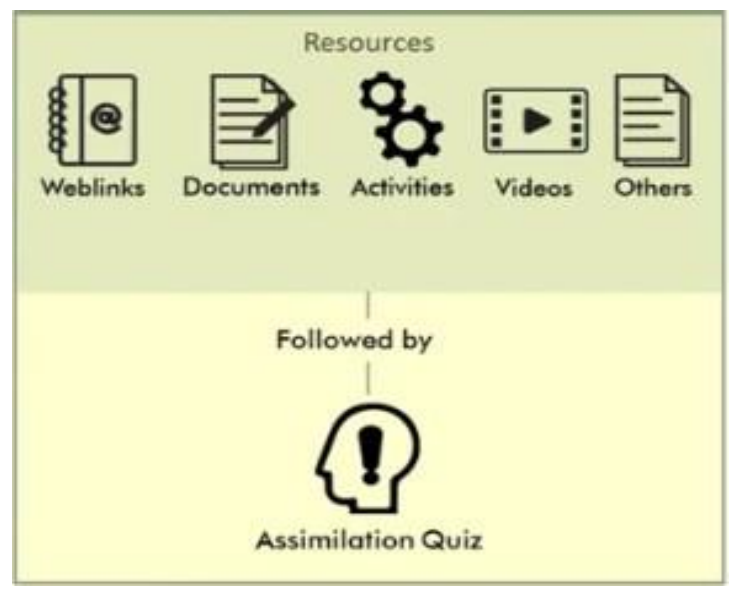

Fig6. LxT Structure

In the Learner Centric MOOC model, the element of Learning Extension Trajectories, that is LxT, is one way to aid a MOOC instructor in addressing the challenge of diversity. The Learning Extension Trajectories is about providing learners with a wide variety of learning resources immediately followed by an assimilation activity.

The resources can be used to support the learner to ensure prerequisites or advance their learning, or support in the direction of their inherent motivation, or support the needs of learners with varying experiences along with taking care of their language or regional context needs. A learning extension resource could be videos, it could be links to various web pages or documents that are already available, or it could also be even research papers that have been written about the topic being discussed.

The learners can access these resources of their choice based on their needs and interest. Following that, learners are required to answer the Assimilation Quiz (AQ) activity which ensures that they have gone through the content in the provided resources. The purpose of an Assimilation Quiz is only to give incentive for access to these resources. Hence the level of questions should be such that anybody who accesses these resources should be able to immediately answer it.

Learning Extension Trajectories enable the learner to increase the depth or increase the breadth of their existing knowledge or understanding, but in addition they cater to diverse type of learners and diverse levels of learning and are followed by a short activity to ensure that learners assimilate the key concept or knowledge intended from the resource[5]. 
Journal of Engineering Education Transformations, Volume 33, January 2020, Special issue, eISSN 2394-1707

DC-DC converter

面 Choppers

'w. types of chopper A-E,multiphase

chopper basics

Chopper A,B,C,D,E

Buck Design

Boost Converter Design

converter

crossword solution

$$
\begin{aligned}
& \text { Phase Controlled Converter } \\
& \text { (PS) Single Phase controller } \\
& \text { (B) } 3 \mathrm{PH} \text { uncontrolled rectifier } \\
& \text { is } 3 \text { phase half controlled rectifier }
\end{aligned}
$$

Fig7. LxT on MOODLE

\section{Creating LxT}

In creation of LxT, scope of diversity, addressing diversity (resources provision) and how to incentivise required to be thought. Following are different type of diversities.

- Regular student and experienced learner i.e. diversity of expertize

- Curious learner i.e. diversity in motivation

- Young and old learner i.e. diversity in age

- Language diversity

Hence decide the priority and address all categories.

LxT helps instructor in requirement and support to decide lower level, depth that can be achieved and variety of topics can be exposed in MOOC. Once scope of diversity is fixed, and then get the resources to address the most important diversity. Resources may be books, YouTube video, OERs and websites but use Creative Commons licensing terms. Also if required take permissions from the resource creator.

For creating Assimilation Quiz following are guidelines.

- Each learning extension trajectory should have an assimilation quiz associated with it.

- Quiz should not be too complex that a person has to spend additional time in finding out the answer.

- Assimilation quizzes have a minor grade associated with it. Marks should not be too high or too low.

\section{Learner Experience Interaction (LxI)}

MOOC learner has discussion forum to interact with the peers as well as the instructors but low participation in the forums because not many people would like to visit that. It leads to non-availability of any peer connection. This makes the discussion forum a utility which is not used to the fullest potential.

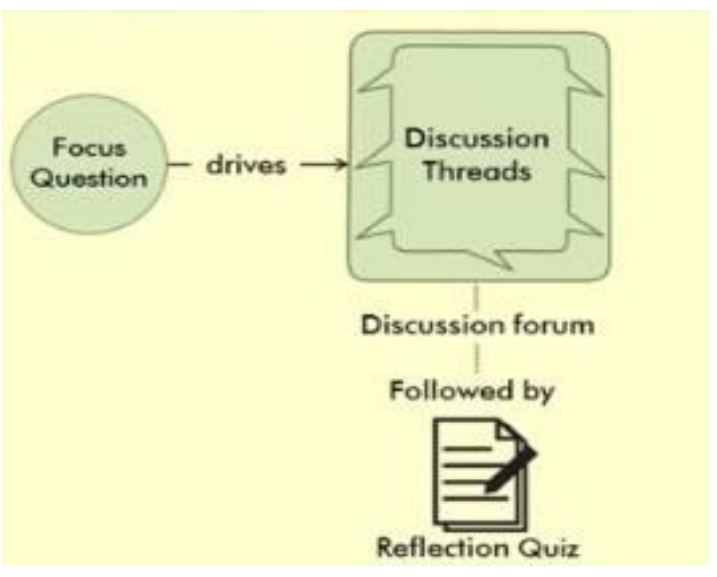

Fig8. LxI Structure

There are three elements of LxI: a focus question, the discussion and the reflection quiz (RQ).The focus question anchors the discussion. It avoids the scatter which can happen otherwise, meaning that the learners are forced to point their discussion posts to the question which is asked, and thereby it sets a very clear deliverable. The discussion thread exposes the learners to the versatile viewpoints. It steers the discussion along the productive channels, because you can find all the related threads at one point now. This encourages participation in the threads of that particular interest for every learner who is trying to access the discussion forum.

The reflection quiz provides a perfect closure to this activity. It also incentivizes the engagement of the learners by making them visit the discussion and answering the quiz questions. In short, an LxI cultivates peer learning via focused discussion. LxI helps the learner not only in participating in the discussion, but also confirming that knowledge by answering the questions in the reflection quiz.

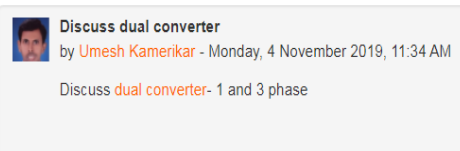

Re: Discuss dual converter

by SHREYAS KURUNDWADKAR - Friday, 18 October 2019, 11:43 AM

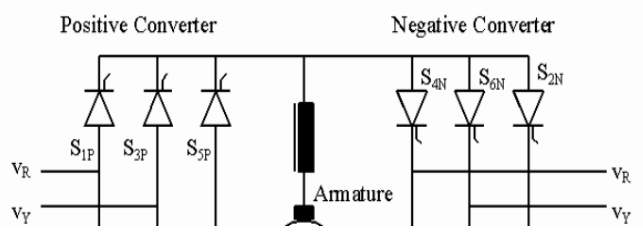


Journal of Engineering Education Transformations, Volume 33, January 2020, Special issue, eISSN 2394-1707

Re: Discuss duai converter
by PRATIK VALIVI. Friday, 18 October 20191128 AM

Dual converter, the name itself says two converters. It is really an electronic converter or circuit
which comprises of two converters. One will perform as rectifier and the other will perform as Which comprises of two converters. One will pertorm as rectitier and the other will perform
nverter. Therefore, we can say that double processes will occur at a moment. Here, two fuli converters are arranged in anti-parallel pattern and linked to the same de 1 oad. These
converters can provide four quadrant operations. The basic block diagram is shown below

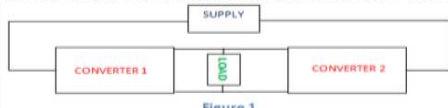

Modes of Operation of Dual Converte There are two functional modes: Non-drculating current mode and circulating mode Non Circulating Current Mode

- One converter will perform at a time. So there is no circulating current between the

- During the converter 1 operation, firing angle $\left(\alpha_{1}\right)$ will be $0<\alpha_{1}<90^{\circ} ; \mathrm{V}_{\mathrm{dc}}$ and $\mathrm{I}_{\mathrm{dc}}$ are

Fig9. LxI Structure using MOODLE

\section{Orchestrating MOOC}

Once the elements of a MOOC are created, it's time to offer it. Orchestration of a MOOC is an important stage in making your MOOC learner-centric. This is because instructor can establish learner connect, get feedback from the learners, act upon it, and adopt your strategies accordingly in a live setup.

\section{Assessment}

Before going ahead with the orchestration, how you would access your students in the MOOC is required to be decided out of LeD, LbD, LxI, and LxT which will be used for assessment. Any or all can be used for this purpose.

One goal of conducting assessment is for students to practice their skills and apply their knowledge. So that, we can continuously analyse their progress and this can be used to improve learning as well as improve teaching. Such assessment is ongoing and frequent and a key element of such assessment is feedback to the learner and feedback to the teacher that helps them improve this teaching and learning process. Assessment for such a purpose is called assessment for learning or formative assessment.

Another reason we do assessment as instructors so that students can demonstrate the achievement of their knowledge and skills. Such assessments describe what a student is able to do and what we value in a course? Assessment for such a purpose is called assessment of learning or summative assessment.

LCM model components can be used for assessment as LeD-Formative assessment

LbD-Summative assessment

LxI-Summative assessment

LxT-Summative assessment

Various elements in a Learner-Centric MOOC model, LeDs, LbDs, LxIs and LxTs can be used for assessment, both formative and summative. These elements can be used to design assessment in different formats, both short or multiple choice type of questions as well as longer questions. As a Learner-Centric MOOC instructor, identify assessment functionalities provided by the MOOC platform and leverage these functionalities to design both formative and summative assessment. Use c certain known techniques to provide effective customized feedback to shorter multiple choice questions. Exploit the power of peer learning and use peer review as a mechanism to tackle scale, while assessing longer questions such as problems.

\section{Results}

It is implemented for some of the points of Power Electronics course final Year B. Tech Students.

LeD reflection sport is implemented using YouTube video with Edpuzzle.

LbD is conducted using Moodle Quiz at the end of unit.

LxT is provided with extra material for study in form of eresources.

LxI implementation is done using Moodle discussion forum with focussed question where students responded to get knowledge and active participation in learning process. Student feedbacks were taken by using MOODLE on different basis to check effectiveness of this technique.

a. Do you like reflection spot for understanding and recalling concept in the LeD?

b. How do you rate Moodle Quiz as LbD activity?

c. Do you find usefulness of other resource material as LxT provided on Moodle?

d. Would you recommend focussed discussion forum as LXI for other subjects?

e. Whether you enjoyed learning and usefulness of the technique?

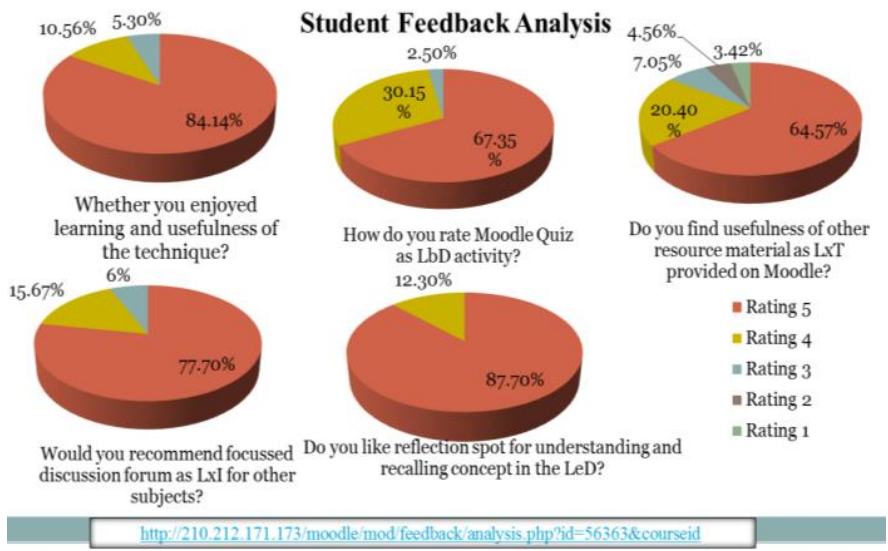

Fig10. Student feedback analysis

Using Moodle Quiz (LbD) In Semester Evaluation (ISE) component conducted which showed significant improvement compared previous year ISE course Outcome (CO) attainment.

\section{Conclusions}

LCM model focuses on learner-centric pedagogy in MOOCs. It is not sufficient for instructor to make their content available and some end assessment to the learner. To ensure learner engagement in a MOOC till end, it is necessary for creators to ensure that learner-centric techniques are followed. The LCM model guides the 

instructors to create learner-centric MOOCs.

The LCM model consists of LeD, LbD, LxI and LxT. This model implementation addresses diversity of students to enrol; complete the MOOC course till end and process of teaching learning will be fulfilled. This improved active participation and learning of students. Also they enjoyed learning in new way using LCM model.

\section{References}

[1] K. Jordan. Massive open online course completion rates revisited: Assessment, length and attrition.(2015) The International Review of Research in Open and Distributed Learning, 16, 341-358

[2] S. Mak, R. Williams and J. Mackness. Blogs and forums as communication and learning tools in a MOOC.(2010) In Proceedings of the $7^{\text {th }}$ International Conference of Networked Learning, 275-285

[3] Sahana Murthy, Jayakrishnan Warriem, Sameer Sahasrabudhe, Sridhar Iyer.(2018) "LCM: A Model for Planning, Designing and Conducting Learner-Centric MOOCs", IEEE Tenth International Conference on Technology for Education (T4E)

[4] Veenita Shah, Gargi Banerjee, Sahana Murthy, Sridhar Iyer.(2018) "Learner-Centric MOOC for Teachers on Effective ICT Integration: Perceptions and Experiences", 2018 IEEE Tenth International Conference on Technology for Education (T4E)

[5] www.emmrccalicut.org

[6] Atul M Kulkarni, Gowrisankar P, K. Madhavi, Johny P Joseph. (2018)"Learning and Reflection of Technology Based Collaborative MOOC Design and Its Evaluation, Validation and Results", IEEE Tenth International Conference on Technology for Education (T4E),

[7] R. Ubell,(2017) "How the Pioneers of the MOOC got it wrong," IEEE Spectrum.

[8] National Research Council. How people learn: Brain, mind, experience, and school: Expanded edition.(2000) National Academies Press.

[9] H. M. Huang.(2002) Toward constructivism for adult learners in online learning environments, British Journal of Educational Technology, 33(1), 27-37.

[10] G. Salmon (2013). E-tivities: the key to active online learning. $2^{\text {nd }}$ edition. Routledge, London, UK.

[11] G. Siemens. (2005) Connectivism: A learning theory for the digital age. International Journal of Instructional Technology and Distance Learning, 2(1), 3-10.

[12] I-C. Hung, Kinshuk and N-S. Chen.(2018) Embodied interactive video lectures for improving learning comprehension and retention. Computers and Education, 117, 116-131

[13] K. R. Koedinger, J. Kim, J. Z Jia, E. A. McLaughlin and N. L. Bier. (2015) Learning is not a spectator sport: Doing is better than watching for learning from a MOOC. In Proceedings of the second ACM conference on learning@ scale (pp. 111-120).

[14] K. F. Hew (2016). Promoting engagement in online courses: What strategies can we learn from three highly rated MOOCS. British Journal of Educational Technology, 47(2), 320-341

[15] M. Bali.(2013), MOOC pedagogy: gleaning good practice from existing MOOCs. Journal of Online Learning and Teaching, 10(1), 44.

[16] Designing Learner Centric MOOC NPTEL IIT Bombay course

[17] www.youtube.com

[18] www.edpuzzle.com 